\title{
ROSSANA ZAERA. RESILIENCIA ARTÍSTICA
}

\section{ROSSANA ZAERA. ARTISTIC RESILIENCE}

Historiadora y crítica de arte, Universitat de València

«Tu visión devendrá más clara solamente cuando mires dentro de tu corazón... Aquel que mira afuera, sueña. Quien mira en su interior despierta.»

\section{RESUMEN}

Rossana Zaera consigue trasladarnos a otro tiempo, un tiempo que rescata y manipula hasta transformarlo en una obra artística. Juega con la percepción, con las palabras, las imágenes y las emociones que la rodean. La delicadeza con la que trata temas tan profundos como el sufrimiento, la muerte o la enfermedad destaca inevitablemente en su obra. Al mismo tiempo, construye un cuento, narra una historia, su historia; ya sea a través de papeles de periódico u objetos. Utiliza lo que cree necesario en cada caso, es decir, lo que considera oportuno para comunicarse mejor, ya sea escribiendo poemas, montando instalaciones, pintando o modelando. Lo que denota la necesidad constante de relacionarse con los demás, mostrar su «yo» más íntimo a través del arte ya que no conoce ni concibe su vida sin él.

Palabras clave: Dolor, creatividad, fragilidad, belleza, esperanza.

\section{ABSTRACT}

Rossana Zaera manages to move us to another time. Instants she rescues and manipulates to turn them into an artistic performance. She plays with the use of perception by words, images and emotions surrounding her. Her work approaches us to affliction, death or disease with a great sensitivity. Simultaneously, she puts up a story using a piece of newsprint or other objects where she narrates a history -her own baggage-. Zaera uses what she judges necessary in every case and what she considers appropriate to get on better by writing poems, making installations, painting, sculpting... This is the way she reveals the constant need of being in contact with others through the necessity of showing her more intimate ego, the one she doesn't conceives her life without.

Keywords: Affliction, inspiration, delicacy, inner beauty, hope. 


\section{Introducción}

El ser humano busca desesperadamente el equilibrio, una estabilidad que se encuentra dentro del campo común de las experiencias compuesto tanto por hechos biológicos como espirituales, que solo unos pocos afortunados logran hallar. Rossana Zaera (Castellón, 1959) es de las que ha sabido canalizar el cruce entre la naturaleza y el espíritu a través del arte y despertar su esencia gracias a un estilo propio inconfundible. Un arte que surge de un proceso de introspección, es decir, parte de sí misma para llegar a los demás. Solamente así logra alcanzar su propia cosmovisión del mundo.

Su obra habla de sí misma pero al mismo tiempo de millones de personas que de una $u$ otra manera se identifican en ella. Zaera construye un paraíso artístico al mismo tiempo que comparte su experiencia vital. Crea un mundo onírico a su alrededor, a través de vivencias y sentimientos que son inherentes al ser humano. Hechos que al día de hoy la hacen ser como es, una artista minuciosa, detallista y delicada que busca y anhela la belleza de todas las cosas.

Cuando se habla de desafíos tanto personales como artísticos, es imposible no aludir a la artista castellonense Rossana Zaera, quien consciente e inconscientemente invita al espectador a la introspección, a la reflexión, a tomar conciencia del ciclo de la vida. Todo se transforma. Zaera nos recuerda a lo largo de su trayectoria que el ser es movimiento o es nada, que hay quien posee una gran capacidad para avanzar, adaptarse y superar cualquier adversidad y aprender mediante la experiencia. Profundiza en el laberinto de la vida, al tiempo que hace hincapié en el concepto de metamorfosis. Su trabajo trata, entre otras cosas, sobre la facultad de los seres vivos para sobreponerse ante cualquier contratiempo. Nuestro cerebro se nutre de los estímulos que le provocan placer pero aprende también de las circunstancias adversas y dolorosas, aunque, asombrosamente, contemos con una gran capacidad para superar y olvidar el dolor. Un dolor que representa y capta, que preserva y rescata del olvido porque, de alguna manera, forma parte de su vida, de su día a día, y, porque inconscientemente su vida va ligada al sufrimiento, como se observa en uno de sus libros más íntimos, Las horas sin luz (2007), concebido como un poema ilustrado por ella misma donde encontramos párrafos como este: «Dolor es herida,/sufrimiento es cicatrización/o gangrena,/pérdida o locura,/pues siempre hay/un pedazo/una concha que el mar/ya no devuelve./Nada temo más/en las horas sin luz.» (Zaera, 2007) Aquí se aprecia claramente la necesidad de la artista a expresar y a compartir sus emociones y pensamientos más íntimos. Solamente trabajando desde su propio interior podrá llegar a transmitir y a despertar sensaciones en los demás 

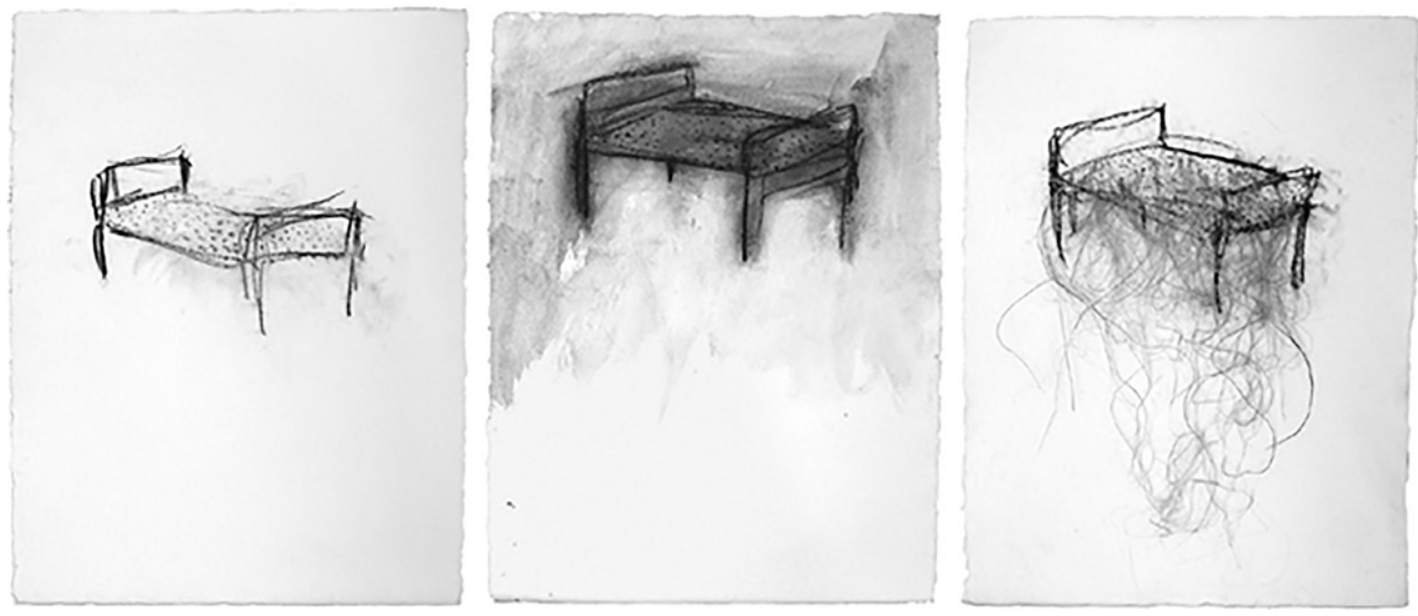

Tres dibujos, serie Habitaciones sin número (200-2001). Pintura sobre papel de algodón. Técnica mixta: Gouache, pastel, collage, tinta china, grafito, 2000. 65 × $50 \mathrm{~cm}$. (Rossana Zaera.

Zaera es una mujer con mayúsculas que no se ha dejado vencer por las adversidades y que ha sabido cómo convertir a través del arte el miedo y dolor en algo positivo. De nuevo, la artista opta por transformar lo abyecto en algo bello. Y para ello, se sirve de la memoria como ella misma explica: «Es verdad que tomo mi propia memoria y mi experiencia vital como punto de partida, pero los temas que trato son universales. Al hablar de la memoria hablo de esa memoria en la que todos pueden reconocerse, porque en todas las vidas hay dolor, sufrimiento, soledad, amor y muerte.» (Gras, 2014). Por eso utiliza casi siempre objetos y elementos del pasado, pero que de una u otra manera han formado parte de su vida; un recorrido que traza a través de su trayectoria artística que, profesionalmente, podríamos decir que empieza con su serie Vivir (1997), punto de inflexión en su carrera, a la que le siguen muchas más, Memorias del infierno (1998), Almagrafías (1998-1999), Dientes y puentes (2000), Habitaciones sin número (2000-2001), Heridas y Fantasmas (2000-2002), SNC, Sistema nervioso central (2007-2008), Habitación 450 (2007-2008), Resiliencias/ Cajas de memoria (2009-201 1), El convite (2007-2010), Mundo interior (2011), La máquina del tiempo (2012-2014), Memoria (2013), Humanas, demasiado humanas (2000-2013), El cedazo-documental audiovisual- (2013), Bajo un trozo de cielo demasiado pequeño (2014), Burkas (2015), Primavera silenciosa (2015), Piedras preciosas (2015) o La novia de tiempo (2015), entre otras. 


\section{Resilencia}

Transgresora y maestra, aúna la creatividad y el sufrimiento, la belleza y la delicadeza, la soledad y la esperanza, creando una atmósfera mágica. Enseña cómo canalizar y trasmutar las emociones y los sentimientos. Hablar de Zaera es hablar, sin duda, de esperanza, que inmersa en toda la obra de la artista alude al concepto de resiliencia, que da título a una de sus series más importantes, y que no es otra cosa que la capacidad misma para vivir. Las imágenes que construye muestran huesos y esqueletos humanos enterrados; en definitiva, reflejan la muerte y lo inerte. Aunque, una vez más, la esperanza ilumina la oscuridad que rodea a la muerte con los brotes que insuflan de nuevo una chispa de vida, plasmando así el sentido cíclico de la vida, su trascurrir, el devenir. En Resiliencia (2006-2010), Zaera se basa en la representación de los conceptos creación/destrucción o desintegración/reintegración y en la recreación de la belleza de la descomposición a partir de la que se genera vida, así como al análisis de la relación entre el ser humano y la naturaleza. Se entremezclan las estructuras anatómicas y fisiológicas vegetales con las humanas con la finalidad de crear vida, y por supuesto, esperanza. Apuesta por la maleabilidad y ductilidad de los elementos que conforman la materia orgánica y, por la fragilidad engañosa que permite perseverar el ser. El profesor Luis Rojas Marcos (Sevilla, 1943) apunta que la resiliencia humana es un atributo natural y universal de supervivencia, que se compone de ingredientes biológicos, psicológicos y sociales, por lo tanto cuando se discute sobre el término psicológico resiliencia se está hablando de vivir. El ser humano, al igual, que la vegetación tiende -en palabras del dramaturgo Maurice Maeterlinck (1862-1949) en La inteligencia de las flores, 1907- a libertarse, a romper la estrecha esfera, inventar o invocar alas, evadirse lo más lejos posible, vencer el espacio en que el destino la encierra, acercarse a otro reino, penetrar en un mundo moviente y animado... Así pues, se debería tomar como ejemplo en la vida diaria el prodigioso esfuerzo de insumisión, de valor, de perseverancia y de ingeniosidad de una flor apunto de florecer con un sin fin de adversidades en contra. La artista misma escribió en referencia a su serie Resilencia en febrero de 2006 :

Hace unos meses soñé con la devastación. Era de noche y caminaba sola por un bosque negro todo quemado. Negro carbón. Los árboles, las piedras, la vegetación, todo estaba calcinado, todo cubierto de oscuridad; pero ante tanta desolación me di cuenta de que entre las piedras y cenizas brotaba tiernamente una ramita con pequeñas hojas verdes muy intensas, y entonces mi asombro dio paso a la esperanza. Comprendí que todo volvería a renacer. Rebelión ante la oscuridad. Obstinación y empeño. De nuevo el árbol de Maeterlinck. (Zaera, 2006) 
Tal y como indica la artista, no hay nada eterno, se evidencia el ciclo de la vida, todo cambia y se transforma. La muerte nutre y engendra vida. Se muestra como de la mismísima profundidad y de la oscuridad renace la esperanza.

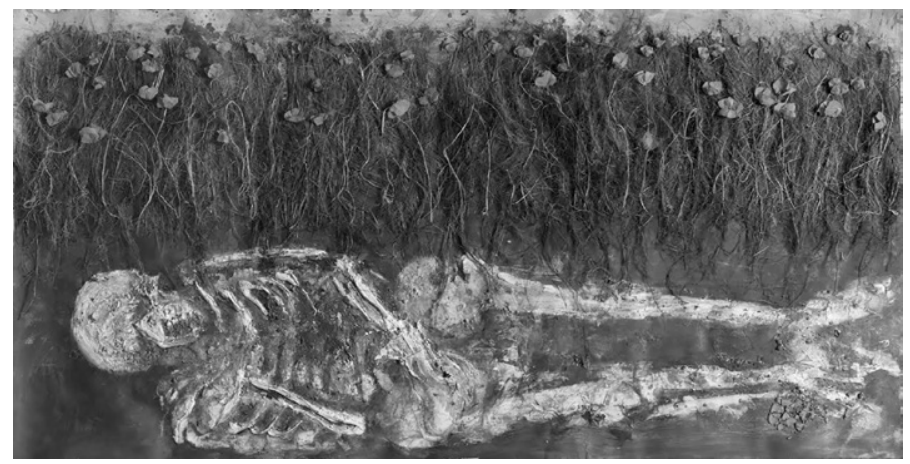

El vaso de barro, serie Resiliencias (2006-2010). Pinturas sobre papel de algodón, Técnica mixta: Gouache, acrílico, pastel, raíces y collage, 2010 [100 x $197 \mathrm{~cm}]$ @Rossana Zaera.

\section{Memoria}

En su serie Cajas de memoria (2009-2010) Rossana Zaera trabaja la memoria de la mano de dramaturgos, poetas y ensayistas como el alemán Friedrich Schiller (1759-1805), el americano Walt Whitman (1819-1892), el belga Maurice Maeterlinck al que recurre de nuevo o el reconocido psiquiatra Luis Rojas Marcos del que se vuelve a servir. Rojas afirma que «La memoria es necesaria para la supervivencia de los miembros del reino animal, pero en los humanos supone mucho más, puesto que poseemos varios tipos de memoria, empezando por las dos más importantes: la verbal y la emocional.» (Rojas, 2010) Sin nuestra memoria seríamos vagabundos errantes en nuestro propio camino. Esa memoria es la que la artista preserva a través de la creatividad, transformando sus vivencias y experiencias en auténticas obras de arte. La castellonense se enfunda en una labor de introspección y retrospección con esta serie donde las cajas consiguen atrapar la esencia de la vida a través de la memoria. Con todo, la caja cerrada alberga todo tipo de emociones y transmite un sin fin de sensaciones, desde dolor, rabia, soledad, ternura, amargura hasta alegría y felicidad. Este conjunto de cajas libera el laberinto emocional de la artista, desata recuerdos y reencuentros con la infancia al mismo tiempo que los preserva y la guarda con recelo en el espacio. 


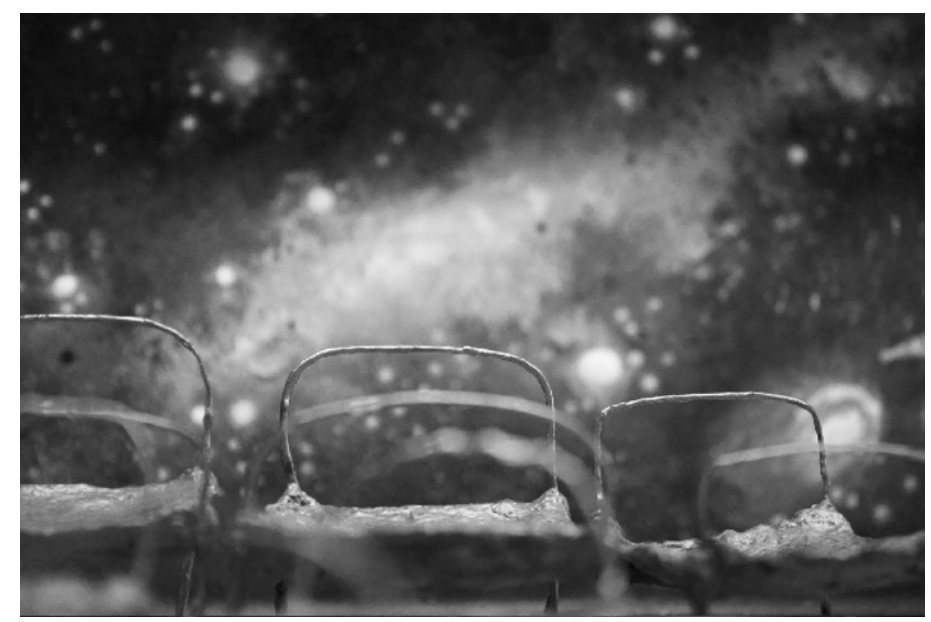

Familia bajo el universo o Caja cuántica, serie Cajas de memoria (2009-2011) Instalación. Caja de hierro, escayola, alambre, estaño, y pintura, 2011 @Rossana Zaera.

Las Cajas de memoria son una puesta en escena, decorados, escenarios de la memoria, es decir, se trataría de la escenografía del entorno físico de la artista, que recrea sus propias vivencias materializadas en las cajas. Esta ejecución paradójicamente remite a lo inmaterial, al mundo onírico de los sueños, en realidad podríamos hablar de objetos poéticos que enfrenta con la mismísima realidad. Cuidadas hasta el mínimo detalle, cada una de las cajas revela un instante, un pensamiento, una sensación. La caja de memoria, Renacimiento (2010) preserva un cerebro humano de la que brota una planta, la vida. Sin duda, un homenaje al renacer, al resurgir y de nuevo a la metamorfosis. En La cuna (2010), vemos cómo la caja se ajusta hasta convertirse en una cuna de bebe mientras que en Hospital infantil (2009) se recrea un hospital con cada una de sus camitas. Sin embargo, una de las más sorprendentes a mi parecer es Familia bajo el universo o Caja cuántica (2011) en la que representa a toda una familia mirando el cielo. Concretamente, esta caja representa a la familia de la artista la su padre, a su madre, a sus dos hermanos y a si misma). Cinco camas, una familia. Una obra que adquiere todo su sentido cuando está cerrada, porque el universo está pintado en el interior de la tapa, ya que el universo para Zaera estaba completo cuando estaban los cinco juntos en casa, sin tener que salir el hogar para ir a trabajar, al colegio, a comprar... De ahí lo de caja cuántica, un universo creado por ella misma y, por lo tanto, idealizado. Puesto que según la física cuántica el observador influye directamente en el resultado de cualquier acontecimiento. 
Tanto en Resiliencias como en Cajas de memoria poetiza el mundo de las emociones a través de la transformación y la reflexión del espacio-tiempo. Conjuga el sentido de la vida y su devenir con la propia introspección. Desarrolla un juego de contrarios, mantiene la tensión entre el origen y el desenlace de la existencia humana mientras pretende preservar y salvaguardar de la destructible muerte los recuerdos, las vivencias y las emociones en una caja de zapatos. Procura así, materializar y transcribir la memoria mientras el cuerpo humano se consume o muta.

\section{Cicatrices}

Asimismo, la naturaleza, el ser humano y la poesía están relacionados a lo largo de toda su carrera, bajo una concepción estética donde se albergan y fluyen los sentimientos y las experiencias. La creatividad, en todas sus formas y manifestaciones, ya sea en la contemplación, la meditación, el arte o la poesía, conforma una forma de comunicación y de acción que también nace y converge en la naturaleza. Es en esa naturaleza donde se produce el conocimiento y donde se provocan sensaciones, limitadas únicamente por las propias creencias y la tradición socio-cultural de cada individuo. A mi juicio, este hecho es más una necesidad del ser que un placer puramente estético, puesto que el ser humano necesita plasmar, es decir, materializar sus emociones y sus experiencias con la naturaleza, en poemas o a través de obras arte.

En el caso en concreto de Rossana Zaera, uno se percata que sus fotografías están trabajadas desde una perspectiva y un conocimiento escultórico-pictórico, donde mayoritariamente suele destacar el equilibrio, la quietud, la belleza, el silencio, y, sobre todo, las formas desde un lenguaje común para los sentidos. Al hablar de belleza aquí, hago referencia a lo que Tomás de Aquino (1224/25-1274) definía como aquello que agrada a la vista -quae visa placet-, que está íntimamente ligado al equilibrio y a la armonía que nos proporciona la naturaleza. Precisamente, esa naturaleza, como decía, puede conducir a sentimientos de atracción y bienestar emocional, en comunión con la propia tradición histórico-cultural, además constituye una experiencia subjetiva en sí misma -el paso del tiempo, la soledad, la violencia o las enfermedades que cada uno de nosotros sufrimos en nuestro cuerpo-. En su serie fotográfica Humanas, demasiado humanas. Las heridas del Alfabeto Natural (2001-2013), cada uno de nosotros puede sumergirse en el mundo cultural de la propia artista que actúa a modo de puente, de conductora de sensaciones y experiencias que nos afectan directa e indirectamente -como el dolor, las heridas o las cicatrices- y que interpreta de manera poética, además de transformarlas en conocimiento. La propia Zaera comentó en una entrevista: 
«Detrás de las heridas descubrí un hermoso alfabeto tan antiguo como el tiempo, universal e impronunciable, cuya fonética guarda en secreto la naturaleza.» (Gras, 2014)

Cada una de las marcas/cicatrices que encontramos tanto en los árboles como en nuestros cuerpos forman parte de un alfabeto natural, según la artista, cuyas grafías asemejan dichas hendiduras y que ella misma ha creado a partir del trazo y el movimiento -típico oriental-, de ese gesto que convierte en manchas de tinta en consonancia a su estado de ánimo y, sobre todo, al silencio. Este hecho le permite jugar con las palabras no dichas, con las ideas y los sueños truncados a causa de las heridas que forman parte de nuestro alfabeto natural -innato-, gracias a la sutileza del tratamiento en cada una de sus obras. Heridas que dejan surcos, marcas, hendiduras y cicatrices que recuerdan y evocan sensaciones humanas. El presente trabajo se caracteriza por una influencia oriental fundamentada-concretamente proveniente del Zen japonés-, puesto que en el acto de plasmar no añade nada, no espera nada; Zaera tan solo pretende reinterpretar su visión del dolor.

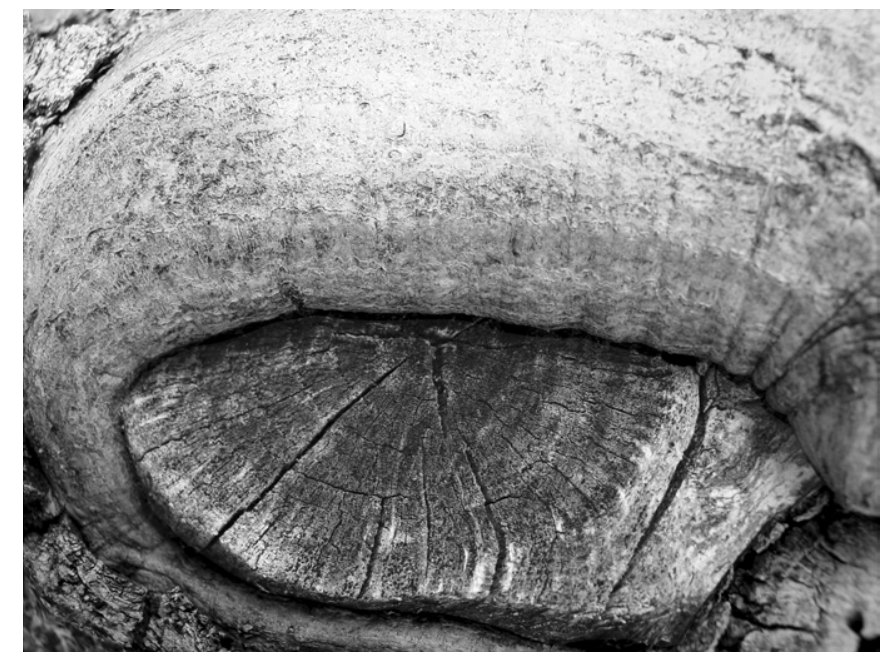

Heridas, cicatrices y otras condecoraciones (2001-2013). Fotografía. ORossana Zaera

El Zen japonés y la naturaleza se caracterizan por la asimetría, la simplicidad, el desequilibrio, la soledad y toda una serie de ideas afines que constituyen los rasgos más característicos del arte y la cultura japonesa. La percepción de la verdad del Zen es «el Uno en los Muchos y los Muchos en el Uno», o mejor, «el Uno permaneciendo como uno en los Muchos, individual y colectivamente», y es precisamente éste el propósito que pretende reflejar ella en sus fotografías. 
Cada rozadura, corte, arañazo o agravio contra la natura se convierte en una afrenta propia; esa aflicción se convierte en acercamiento, en semejanza, en vida, en definitiva. «He encontrado en la naturaleza unas heridas bellísimas. Nunca hubiera imaginado lo parecidas que son a nuestras cicatrices, y con cuanta similitud nos las curamos» (Zaera, 2013), remarca la artista. Esta es una obra en la que se destaca el hecho de que cada nudo de árbol posee una belleza intrínseca y única como la de cada uno de nosotros. Al mismo tiempo, debemos tener en cuenta que siempre acaba curándose y brotando de nuevo, otra característica común a nuestra cultura, si entendemos por cultura todo aquello que hace de la vida algo digno de ser vivido como apuntó el poeta y escritor estadounidense T. S. Eliot (1888-1965) en su día; es decir, las heridas y las cicatrices nacen de las múltiples experiencias que nos brinda la vida, en la que es inevitable sufrir en algún momento y forman parte, inexorablemente, de nuestra condición de seres vivos.

\section{5. ¿Cómo trabaja Rossana Zaera?}

Durante la conversación que mantuve con la artista en 2014 me confesó que no tiene establecida ninguna rutina de trabajo y que suele trabajar en más de un proyecto a la vez. Filósofa, artista plástica, diseñadora gráfica o escritora, son algunas de las facetas que encontramos en Rossana Zaera, pero ante todo, se trata de un ser humano, una mujer que experimenta y acumula recuerdos que cobran vida a través de zapatos, de cajas, de instrumentos quirúrgicos o de bordados, que reflejan su propio mundo interior, un mundo que comparte a través de sus obras y, sobre todo, con talleres que ofrece a todo aquel que esté dispuesto a querer escucharse y aprender. Talleres como Laberintos Interiores donde la atmósfera que se respira es relajada y armoniosa, algo que también se llega a percibir en cada una de sus obras. Con todo, la artista crea un espacio genuino dentro y fuera de su estudio, un cosmos que gira en torno a la sutileza, la seducción, la melancolía...

Enamorada de la belleza, de la vida y la poética que ésta encierra, Zaera no duda en embarcarse en distintos proyectos, documentales, libros de artista e incluso escribir e ilustrar un cuento infantil junto a su hijo Miguel, Tiburones de agua dulce (2002). Detallista hasta la médula, cuida minuciosamente sus presentaciones y cuando la dejan diseña y maqueta sus publicaciones como autora. Es, sin duda, una artista multidisciplinar. Inquieta y curiosa, atesora todo tipo de objetos -recuerdos- que sabe cómo utilizar llegado el momento. Incansable y luchadora no deja de innovar y experimentar con todo tipo de materiales y técnicas. Evoluciona con cada nuevo reto que se fija, siempre en continua evolución.

De forma sorprendente, Zaera nos traslada a otro tiempo, un tiempo que rescata y manipula hasta transformarlo en una obra artística. Juega con la percepción, con las palabras, 
las imágenes y las emociones que la rodean en su cotidianidad. Quizá por ello destaca la delicadeza con la que trata temas tan profundos como el sufrimiento, la muerte o la enfermedad que, inevitablemente, debemos afrontar y nos acompañan a lo largo de nuestra existencia. Al mismo tiempo, construye un cuento, narra una historia, su historia; ya sea a través de papeles de periódico u objetos. Utiliza lo que cree necesario en cada caso, es decir, lo que considera oportuno para comunicarse mejor, ya sea escribiendo poemas, montando instalaciones, pintando o modelando. Lo que denota la necesidad constante de relacionarse con los demás, mostrar su 'yo' más íntimo a través del arte ya que no conoce ni concibe su vida sin él.

Desde su infancia no comprende otra forma de expresarse y compartir su visión del curso vital que no sea el arte. Un curso en el que se crece, se ríe, se sueña y se llora, porque no todo en la vida es un camino de rosas, siempre hay tropiezos, envidias, errores y sorpresas inesperadas, buenas y malas. Y para ello, se precisa del consuelo, el amor o la belleza que encontramos en la poesía que emana de cada una de sus piezas.

Su obra habla, pues, como he comentado antes, de la metamorfosis, transforma objetos, herramientas o instrumentos, juega con sus posibilidades hasta convertirlos en elementos estéticamente bellos, agujas hipodérmicas se mudan en mariposas o libélulas como podemos observar en Nuevos no-nociceptores (2013). Al mismo tiempo las camas de hospital, tan presentes en su obra, representan personas, los números, los juguetes, las cajas de zapatos o habitaciones se convierten en receptáculos que encierran y preservan recuerdos que la artista desvela a través de múltiples metáforas contenidas en su imaginario visual. Zaera muestra la desesperación, la tristeza o la resignación confrontada con la elegancia, la seducción y la fuerza que entraña la naturaleza en sí misma.

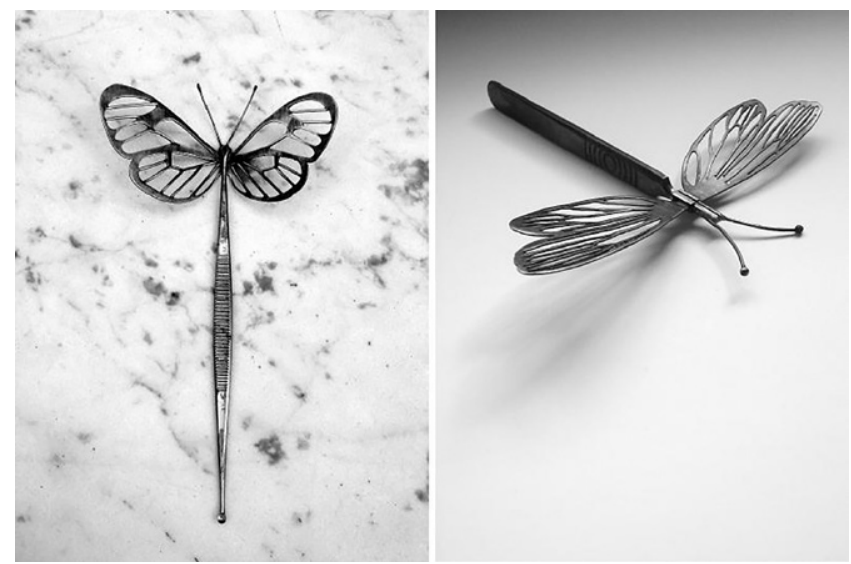

No-nociceptores (2004-2013). Instrumental quirúrgico, acero y plata. @Rossana Zaera 


\section{Transgresión}

La transgresión en su obra radica en el tratamiento, en el proceso, en la manera de elaborar cada una de sus piezas, donde el resultado acaba siendo sublime. En su obra podemos hablar perfectamente del concepto de belleza si por bello entendemos aquello que complace a los sentidos y, por extensión, al espíritu.

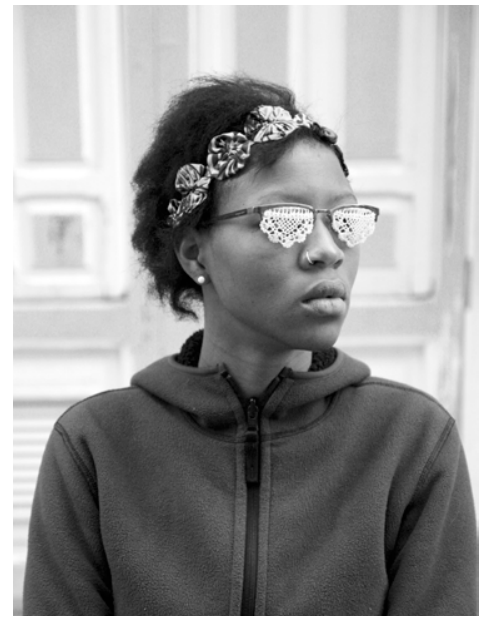

Sophie, serie Burkas, fotografía, 2015 ORossana Zaera

La artista a través de sus imágenes trabaja el valor cultural de hechos literarios o denuncias sociales a través de la suavidad, la elegancia, la quietud y el silencio; trasladando al espectador a un universo sublime donde la imaginación no tiene fin como por ejemplo en Burkas (2015). En la que pretende trasmitir cómo se ve el mundo a través de una rejilla, las sensaciones que tienen las mujeres en situaciones muy diversas a través del burka, ya sea ir a comprar, leer un libro, dar de mamar, etc. Para ello elabora unas gafas confeccionadas con puntillas que pertenecían a su abuela. Gafas que le regalan, encuentra o compra en mercadillos, se transforman en el perfecto soporte.

Anteojos que recubre de ganchillo y que distorsionan la realidad, ya que se recibe una visión sesgada. El resultado al reemplazar el cristal por las puntillas es realmente poético. Pero no deja de ser una denuncia social a un hecho con el que la artista se siente comprometida. Por lo que trata de experimentar lo que deben sentir todas esas mujeres que no se reconocen en una sociedad en la que viven ocultas, tras una rejilla que

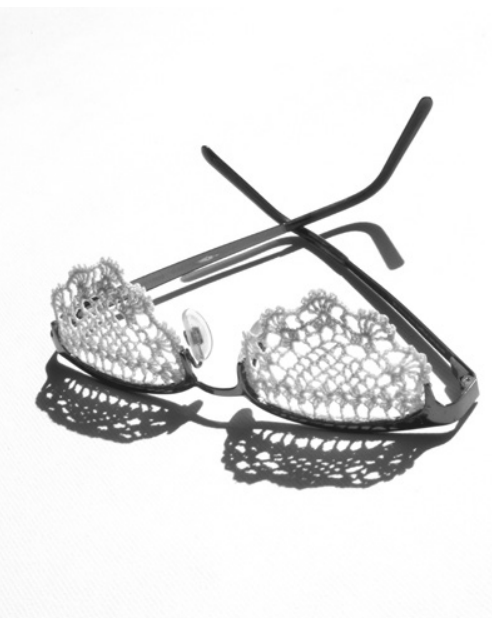
les impide percibir y sentir la vida sin interferencias. La misma artista explicó en la revista Asparkía:

Burka de Sophie, serie Burkas, fotografía, 2015 CRossana Zaera 
Hace un tiempo vi la fotografía de un grupo de mujeres con burka. Eran estudiantes de una universidad del Oriente Medio que acababan de graduarse. Me pregunté como se reconocerían a sí mismas y a sus compañeras, con el cuerpo y la cara cubiertas por completo. Esto me hizo reflexionar. Pensar en cuantas mujeres occidentales llevan burkas invisibles bajo los cuales terminan disolviéndose, aunque no se les imponga llevar aquella fantasmagórica vestimenta. ¿Cómo podría materializar este pensamiento? Lo más terrible del burka era esa especie de rejilla para disimular los ojos, a través de la cual las mujeres están obligadas a ver y a mirar el mundo. Mi madre me había hecho un regalo precioso, una caja de zapatos llena de las puntillas de ganchillo y encajes de bolillos que hacía mi abuela. Allí encontré la solución. (Zaera, 2015: 9)

Al mismo tiempo, se atrevió a realizar también en 2014 un homenaje al tema del suicidio y sus víctimas, uno de los más controvertidos y que todavía hoy continúa siendo tabú en nuestra sociedad. Bajo un trozo de cielo demasiado pequeño es una obra que resulta extremadamente bella. La artista sugiere el suicidio sin mostrar signos de violencia. Tan solo coloca una soga suspendida de la que suavemente penden unas hormas de zapato rematadas por lágrimas de cristal que brillan provocando múltiples destellos, creando un gran efecto poético, un inmenso complejo de recuerdos y emociones que se agolpan y se apoderan del espectador. Zaera trabaja sobre una cultura poética así como una vida llena de formas y sueños (que nos produce una sensación, que llega hasta dentro, y que invade nuestros sentidos). Sensaciones y efectos como los que nos traslada con sus títulos, evocadores y sugerentes, que encierran y construyen un poema en sí mismo como en este caso en concreto.
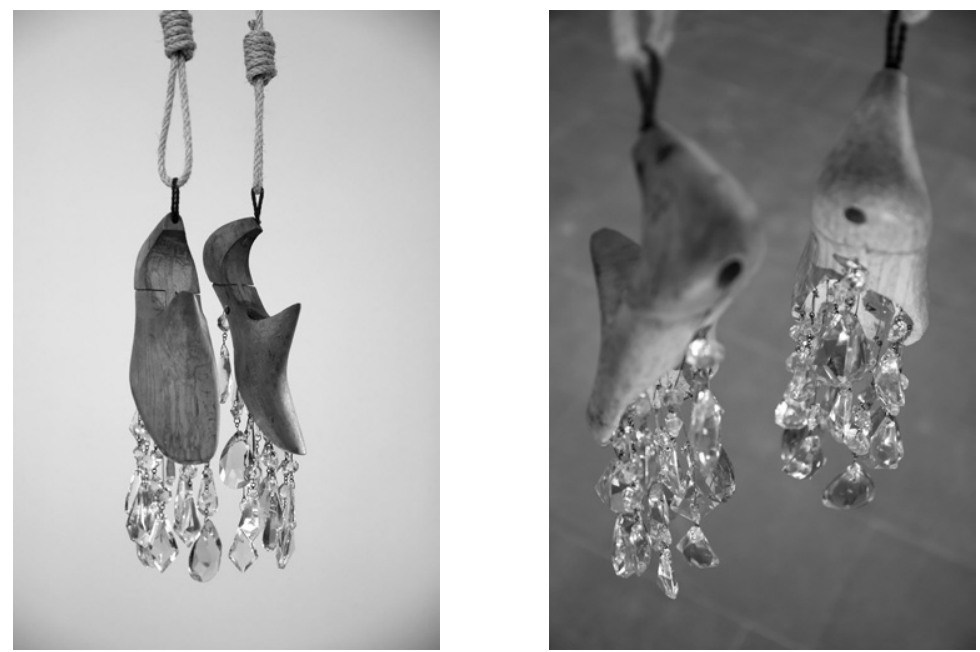

Bajo un trozo de cielo demasiado pequeño, cuerda, hormas de zapato y cristal, 2014 @Rossana Zaera 
En Novia de tiempo (2015), una de sus últimas piezas, trabaja sobre el paso del tiempo y el proceso de envejecimiento. Una obra de la que se siente particularmente satisfecha y orgullosa. En mayo de 2015 por fin pudo llevar a cabo la idea que concibió años atrás; un proceso que materializó y culminó durante el verano. Una pieza que bien podría desfilar en las mejores pasarelas del mundo, ya que está concebida como un vestido de alta costura. Posee un corte básico y una confección típica de un vestido de cola, como el de cualquier novia. Aquí la suavidad del raso o la seda se transforma en una textura áspera que le otorga la combinación de arpillera y esparto. Trabajo laborioso y manual, la artista pasó muchas horas sentada en el suelo cosiendo esta maravillosa capa que culmina con una cola que arrastra el bagaje de toda una vida; una vida en la que ha pasado el tiempo, donde cualquier mujer se ha convertido en algún momento en esposa, madre, víctima, amante, etc. Inconscientemente, uno tiende a identificarse con esas mujeres porque, en el fondo, todos formamos parte de ellas.
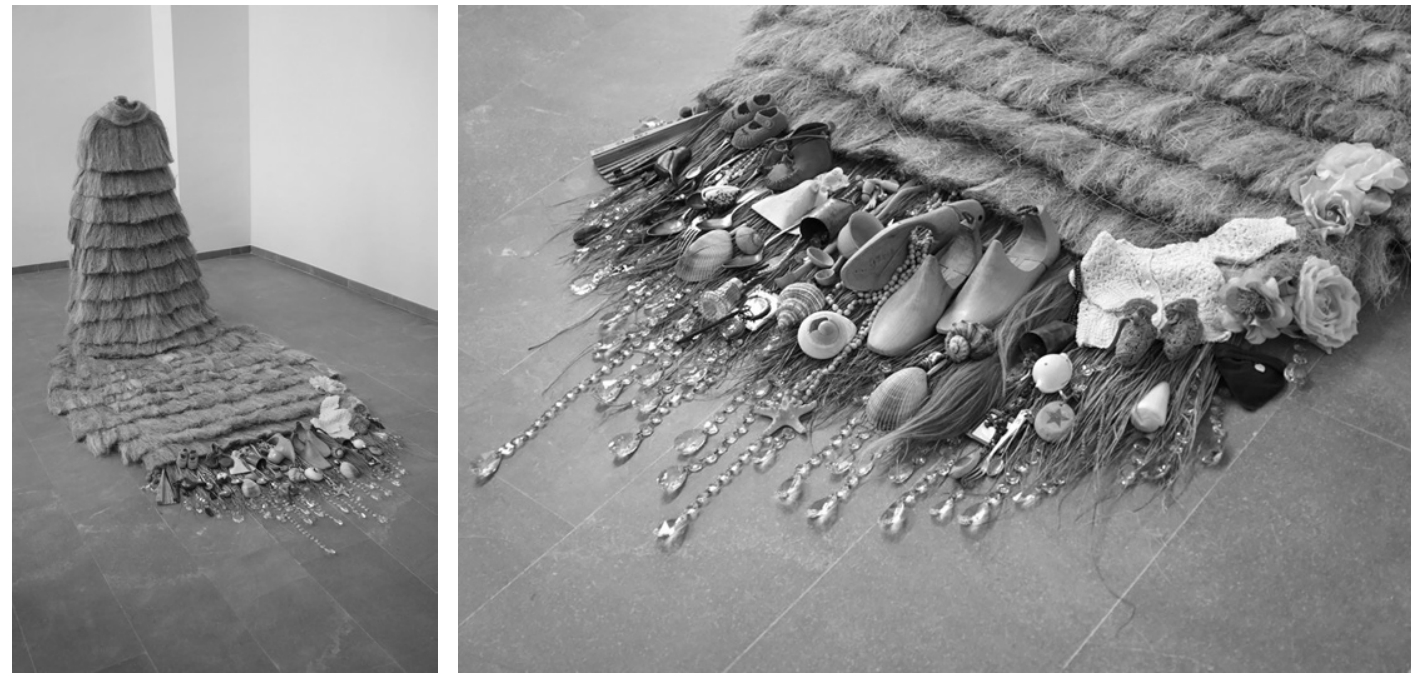

Novia de tiempo, Técnica mixta, 2015@Rossana Zaera

El tiempo no perdona a nadie, somos iguales ante él. Todo ser sufre injusticias, tiene vivencias dolorosas y traumáticas pero también experiencias dichosas que le acompañan a lo largo de la existencia. Amas, lloras, ríes, gritas porque estas vivo, en definitiva, Zaera compone una carta de sensaciones que arrastran lágrimas de cristal, sueños que representa con caracolas de mar, secretos que atesora en pequeñas bolsitas, hormas de zapatos que vienen 
acompañados de decisiones, risas en familia con cucharas, el paso del tiempo simbolizado por relojes, juguetes y ropa de bebé que retrotraen a la infancia... Todo ello sobre un maniquí al que desnuda y le arranca la espuma dándole una nueva textura para acto seguido pintarlo hasta lograr el efecto rojizo de cobre antiguo. Una obra que destaca e incide en la palabra novia y lo que ello connota, es decir, un periodo feliz, libre de compromisos maritales y del peso del tiempo. Un tiempo que irremediablemente es efímero. Y que se contrapone con obras como la de La perfecta casada (2001) de Elena de Rivero (Valencia, 1952) que gira en torno a un enorme velo de novia sobre el que se han cosido las páginas de la obra de Fray Luis de igual título impresas en tela. En cada página cosida se ha tachado pespunteado cada línea, al igual que aparecen de nuevo pistas de una iniciación. Pistas para una nueva poética feminista que se apropia de los roles asociados al género femenino y, subvirtiéndolos, los convierte en seña de una nueva forma identitaria. Pero si algo comparten estas dos artistas valencianas es la manera de trabajar, a las dos les gusta coser y utilizan todo tipo de objetos y telas que cosen, pegan o transforman con un único propósito, embellecer la pieza y transformar lo cotidiano en sublime o lo feo y doloroso en un algo bello.

En Primavera silenciosa (2014-2015) y en Piedras preciosas (2015), vuelve a trabajar con agujas hipodérmicas. Asociadas con el dolor y la enfermedad, Zaera juega con ellas hasta transformarlas en algo bonito que desprende fragilidad. En Primavera silenciosa cada
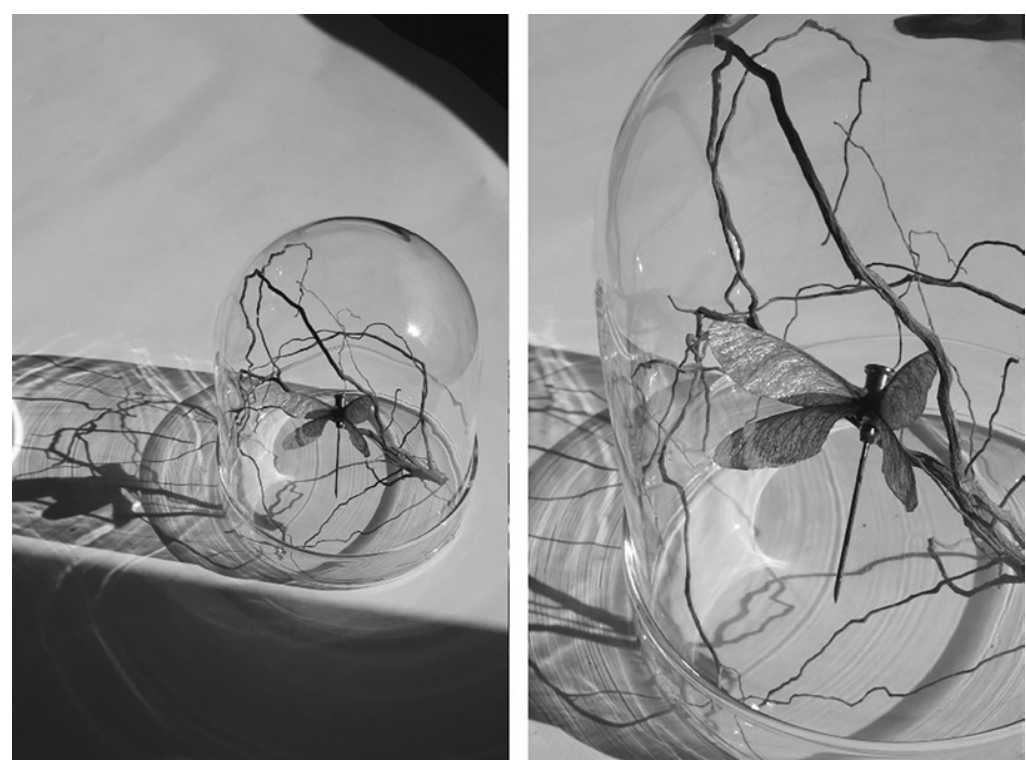

Primavera silenciosa, aguja hipodérmica y semillas, 2014-2015 @Rossana Zaera 
una de las agujas se convierte en una preciosa y brillante libélula compuesta con semillas de arce. Delicadeza extrema. De nuevo, Zaera sólo esboza el camino a seguir, nos guían, es el público quien debe hacer el resto, por lo que su interpretación es abierta y su belleza libre. Sus obras son autosuficientes y sugestivas. Manifiestan en alto grado las cualidades propias de la poesía, como la idealidad, espiritualidad y la belleza; su lenguaje o, lo que es lo mismo, su manera de expresarse, configuraría su propio estilo poético. En Piedras preciosas retoma el símbolo de la cama a la que clava diversas agujas que corona con piedras preciosas de distintos colores. Piedras que brillan y le confieren un valor que eleva a la aguja a obra de arte y a su vez en joya, como cualquier trabajo de orfebrería de antaño donde se incrustaban piedras preciosas.

\section{Conclusiones}

La artista basa su trabajo e investigación en la necesidad de comunicarse y expresarse mediante un lenguaje reconocible y accesible por todos, el arte, bajo una mirada femenina -intrínseca, sencilla e íntima. Los «poemas visuales» que surgen del interior de sus obras son como pequeños tesoros que se antojan evocadores. Pero si por algo se caracterizan es por la delicadeza, la fragilidad y la pureza que emanan sus piezas, metáforas visuales que se contraponen a una sociedad estresada, mediatizada y violenta.

\section{Bibliografía}

Elot, Thomas Stearns (1948): Notas para la definición de la cultura, Madrid: Encuentro, 2003. CAGICAS, Ángel y Rossana ZaERA (2001): Habitaciones sin número A Jose Luis Verdes in memorian, Jaen: Universidad de Jaén.

(2010): Resiliencias / Cajas de memoria, Castellón: Galería Octubre, Universidad Jaume I.

Carrión, Ignacio y Rossana Zaera (2007): Fantasmas que nos habitan, Sagunto: Centre Cívic Antic Sanatori.

FluXÀ, Lluc y Rossana ZAera (2014): Humanas, demasiado humanas. Las heridas del alfabeto natural, Palma de Mallorca: Lluc Fluxà. Projectes d'Art. Espai HC. 
Gras CRUZ, Irene (2014): «Rossana Zaera: memoria poética» Publicado el 21 de abril de 2014. http://irenegrascruz.com/2014/04/21/rossana-zaera-me-moria-poetica/ [Consultado 16 de noviembre 2015]

JaraUta, Francisco y Rossana Zaera (2000) Anatomías / Restauración, Valencia: Palacio de Colomina. Fundación Universitaria CEU San Pablo.

RoJAS, Luis (2011): Superar la adversidad, Madrid: Espasa.

ROSENFELD y Rossana ZaERA (2009): II nero non è solo buio, Napoli: Galleria Napolinobilissima. TORRent, Rosalía y Rossana Zaera (2010): El convite, Castellón: Art Dam.

ZAerA Rossana «Rossana Zaera», http://www.rossanazaera.com/ [Consultado 16 de noviembre 2015]

2014. http://irenegrascruz.com/2014/04/21/rossana-zaera-me-moria-poetica/ [Consultado 16 de noviembre 2015] (1987): Itinerario de Vórtices, Cuaderno de viaje (de 1982 a 1987), Castellón: Tengo que irme. (1998): Vivir, Valencia: La Imprenta.

(1999): Pensamientos como hojas, Comunicación gráfica, Valencia: La Imprenta. (2002): Crisálidas, Comunicación gráfica, Castellón: Ellago ediciones. (2002): Tiburones de agua dulce, Valencia: Tàndem ediciones. (2004): El sueño de Pati, Comunicación gráfica, Valencia: La Imprenta. (2007): Las horas sin luz, Colección Cuadernos de Malabaria, Castellón: Tengo que irme. (2015): «Burkas», Asparkía. Investigación feminista, Núm. 26, Castellón: Institut Universitari d'Estudis Feministes i de Gènere, Universitat Jaume I Purificación Escribano, llustraciones, pp. 1-209. 